\title{
EL CAPITALISMO COMO FUENTE DE INJUSTICIAS EN LA OBRA PÓSTUMA MORAL SOCIAL DE SAN ALBERTO HURTADO. CLAVES QUE PUEDEN INSPIRAR LA COMPRENSIÓN DE LA CRISIS CHILENA ACTUAL DESDE EL DIÁLOGO FE Y POLÍTICA
}

\author{
CAPITALISM AS A SOURCE OF INJUSTICE IN THE \\ POSTHUMOUS WORK MORAL SOCIAL OF SAINT ALBERTO \\ HURTADO: KEYS THAT CAN INSPIRE AN UNDERSTANDING \\ OF THE CURRENT CHILEAN CRISIS FROM THE DIALOGUE \\ BETWEEN FAITH AND POLITICS
}

\author{
SOLEDAD ARAVENA ARAVENA* \\ Mg. en Teología Fundamental \\ Universidad Católica de la Santísima Concepción, Chile
}

Artículo recibido el o2 de marzo de 202I; aceptado el o7 de julio de 2021 .

*saravena@ucsc.cl

https://orcid.org/oooo-0002-I545-2777

Cómo citar este artículo:

Aravena, S. "El capitalismo como fuente de injusticias en la obra póstuma Moral Social de San Alberto Hurtado. Claves que pueden inspirar la comprensión de la crisis chilena actual desde el diálogo fe y política" en Palabra y Razón. Revista de Teología, Filosofía y Ciencias de la Religión. № 19 JULIO 202I, pp 77-IO2 https://doi.org/I0.29035/pyr.I9.77 


\title{
RESUMEN
}

A partir de la lectura a la obra Moral Social de San Alberto Hurtado, el objetivo de este artículo será mostrar, a modo de ensayo, la necesaria relación que debe existir entre fe y política, para mantenerse alertas a regímenes generadores de injusticias sociales como el capitalismo. Después de situar la problemática desde la relación entre la fe y la política, se analiza la crítica del santo jesuita hacia el capitalismo y el liberalismo con el fin de esbozar algunas ideas que reflejen la actualidad del pensamiento de Hurtado, en torno a tres aspectos: la Doctrina Social de la Iglesia, la realidad eclesial chilena post-dictadura y la acentuación de la justicia y caridad como respuesta al capitalismo.

Palabras claves: fe / política / capitalismo / Iglesia chilena / justicia social / crisis social

\begin{abstract}
From the review of the work Moral Social by San Alberto Hurtado, the objective of this article will be to show, as an essay, the necessary relationship that must exist between faith and politics, in order to stay alert to regimes that generate social injustices such as capitalism. After situating the problem from the relationship between faith and politics, the critic of the Jesuit saint towards capitalism and liberalism is analyzed in order to outline some ideas that reflect the actuality of his work concerning three aspects: the Social Doctrine of the Church, the post-dictatorship chilean ecclesial reality and the emphasis on justice and charity as response to capitalism.
\end{abstract} crisis

Keywords: faith / politics / capitalism / chilean church / social justice / social 


\section{Introducción}

Un reconocido abogado y columnista de medios periodísticos chilenos, Carlos Peña, escribió una columna en el periódico El Mercurio, que tituló Perdidos en la noche en la que critica el rol que han tenido diversas instituciones sociales y culturales frente a las dos grandes crisis que ha atravesado Chile entre el 2019 y 2020, a saber, la crisis del Estallido Social del I8 de octubre y la crisis sanitaria por la pandemia mundial, respectivamente. Para el columnista, estas instituciones son principalmente la política y la religión. Ambas configuran la vida pública y privada del ser humano; en palabras de Peña, "existen dos prácticas sociales capaces de reconocer la incertidumbre y, por decirlo así, convivir con ella y domesticarla: la política y la religión"'. Sin embargo, enfatiza, que ambas han estado ausentes en la esfera social y no han sabido responder a las incertidumbres más profundas del ser humano frente a las crisis.

Pero, ¿es cierto que la Iglesia ha permanecido en silencio en estos últimos años frente a las crisis que hemos vivido como país? Si es así, ¿a qué se debe? El panorama para la Iglesia en Chile, así como para Occidente entero -incluyendo Latinoamérica-, no ha sido fácil. A los problemas que ha vivido Chile, en estos últimos dos años, hay que sumar la crisis que ha enfrentado la Iglesia Católica en los temas de abusos, que han calado hondamente en el sentir y el corazón de los cristianos, así como de la sociedad chilena en general ${ }^{3}$. Sin embargo, esta no es la única crisis que ha debido enfrentar la Iglesia Católica en estos últimos siglos. El siglo XX ha sido el siglo de la modernidad y de la secularización. En este sentido, la vida se ha tornado menos religiosa debido a que se han separado los espacios sagrados de la vida del hombre común. La secularización puso a la Iglesia en una férrea defensa de su posición de poder en la sociedad occidental, despreocupándose por los dolores propios de las víctimas de la modernidad: los excluidos de los sistemas económicos y de los avances de la modernidad, con todo su aparataje tecnológico y monetario. Fenómeno que se vio agravado por el influjo de la globalización y el capitalismo. La Iglesia abandonando al más débil, dejó la puerta abierta para que el pueblo, otrora fiel al cristianismo, se transformara incluso en su férreo opositor.

\footnotetext{
I Carlos Peña, «Perdidos en la noche», El Mercurio, 28 de junio de 2020.

2 Peña, «Perdidos en la noche».

3 Para mayor información, Comisión UC para el Análisis de la crisis de la Iglesia Católica en Chile, Comprendiendo la crisis de la Iglesia Chilena. Documento de análisis (Santiago: Pontificia Universidad Católica de Chile, 2020), https://www.uc.cl/site/efs/files/II465/documento-deanalisis-comprendiendo-la-crisis-de-la-iglesia-en-chile.pdf
} 
Este contexto motiva a redescubrir el pensamiento de san Alberto Hurtado (†190I-I952) quien, en su tiempo, anunció y denunció en sus diversas obras, el silencio de la Iglesia, dejando entrever su preocupación por la misión de la fe cristiana, así como por los más desfavorecidos de sistemas económicos modernos como el capitalismo. En su libro ¿Es Chile un país católico?, una de sus obras más conocidas -y tambien en sus constantes discursos y escritos-, da cuenta no solo de los graves problemas de desigualdades sociales que vivió Chile en su época y la falta de preocupación real de la Iglesia Católica chilena, sino que, al mismo tiempo, augura proféticamente las profundas grietas generadas entre el pueblo y la Iglesia. Por esto, la urgencia de Hurtado es buscar un Chile más justo, donde la caridad y la justicia trabajen armónicamente en pos del bien común.

Si bien muchos de sus escritos apuntan a estos temas, es en la obra Moral Social donde los sistematiza con mayor agudeza. Se trata de una obra póstuma inconclusa de Hurtado donde destaca la relevancia de la relación fe y política que encierra y las preocupaciones del mismo autor respecto de la cuestión del capitalismo. Sin embargo, es una obra que, leída a la luz de sus otros textos, puede ser considerada una verdadera carta de navegación para buscar pistas de la relación entre fe y política, que ilumina la búsqueda de la justicia y la caridad, como semillas propias del Reino de Dios preparado por Cristo, en nuestro actual contexto de silencio de las estructuras, como señala Peña, las cuales debiesen ser garantes de respuesta a las injusticias del hombre común y del hombre social.

La intención de esta investigación será mostrar, en primer lugar, la importancia que da Hurtado a la relación entre fe y política, y su necesidad en la reflexión cristiana, tomando en cuenta el contexto social, político y religioso desde que el autor reflexiona. En segundo lugar, se identificarán las diversas críticas que realiza en su obra Moral Social, al régimen capitalista considerándolo un régimen injusto y generador de desigualdades sociales, contrario a un pensamiento cristiano que busca anunciar el Reino de Dios henchido de justicia y caridad. Y, en tercer lugar, se verán, por un lado, una crítica a la Doctrina Social de la Iglesia (DSI), necesaria desde un punto de vista general, porque como materia católica ha tenido fallas con repercusiones respecto de la visión del capitalismo; y, por otro lado, una breve contextualización del Chile post-dictadura, que servirán de preámbulo para proponer la vigencia de Alberto Hurtado frente a un sistema social y político injusto. Ciertamente, el presente artículo no mostrará los problemas actuales de las crisis que 
ha experimentado Chile, en materia, política, económica y religiosa; no obstante, los elementos aportados por Hurtado, así como la breve crítica a la DSI y al contexto de Chile desde la vuelta a la democracia, pueden servir como claves de atención.

\section{La relación fe y política en la obra Moral Social de Alberto Hurtado}

Uno de los temas fundamentales de Alberto Hurtadofueron las demandas sociales y políticas. Por esto, constantemente, instó a los católicos a tomar posición desde su fe a los problemas sociales que enfrentaba Chile a mediados del siglo XX. Una lectura atenta a las observaciones que hizo Hurtado al Papa Pío XII, en 1947 sobre la situación social de Chile ${ }^{4}$, sirven como un marco contextual de su obra Moral Social:

Con espíritu de filial confianza me permito someter a V.S. algunas observaciones sobre la situación social de Chile, mi país de origen, animado por los llamados de V.S. a una acción inmediata que sea la obra de todos los hijos de la Iglesia. En mi opinión el mayor peligro está en que parecemos no darnos cuenta del peligro. Creemos estar todavía en un país profundamente católico y se piensa que las agitaciones sociales son efecto del oro ruso únicamente y que la propaganda protestante no es sino el resultado del dólar americano. Los sacerdotes y aun los Obispos, no parecen darse bien cuenta de la inmensa tragedia que nos va a coger desprevenidos 5 .

\section{I. El contexto social y político en el que emerge la obra Moral Social: una lectura desde Hurtado}

Las mencionadas observaciones, que Hurtado hizo a Pío XII en 1947, se sintetizan en los siguientes tópicos: situación social, religiosa y política en Chile ${ }^{6}$.

Sobre la situación social de Chile, San Alberto expone a su Santidad las grandes diferencias sociales y humanas del país en la década del 40. Latifundistas que tienen el 50\% de las tierras (no más de Iooo familias)

\footnotetext{
4 Cf. «Memorial del Padre Hurtado a Pío XII», en la web oficial sobre el Padre Alberto Hurtado, acceso el 25 de junio de 2020, https://www.padrealbertohurtado.cl/memorial-del-padre-hurtadoa-pio-xii/. Informe entregado por el Padre Hurtado a S.S. el Papa Pío XII en una audiencia privada el I9 de octubre de 1947, para pedir su autorización para fundar la Acción Sindical y Económica Chilena. Recién se conoció a comienzos de los noventa, cuando comenzó su proceso de canonización.

5 «Memorial del Padre Hurtado a Pío XII», en la web oficial sobre el Padre Alberto Hurtado.

6 Lo que se pretende con este apartado es entrar exclusivamente al análisis de Hurtado, presentado a Pio XII, para contextualizar el trasfondo de la obra Moral Social.
} 
y una población campesina completamente empobrecida tratada como si vivieran en la época feudal, sin ningún acceso real a mejorar sus condiciones de vida ni acceso a la educación. Señala que la Iglesia Católica no ha prestado real atención a las necesidades de los más desposeídos y, lejos de eso, se ha centrado en combatir las ideologías comunistas, que a su vez tienen coaptado al campesinado en casi un $80 \%$ de sus sindicatos, y el otro $20 \%$ los socialistas. Con gran pesar, Hurtado dice que no existe ninguna organización de inspiración católica y que los obispos, en vez de prestar atención a los problemas que afectan a la gran mayoría del país, han simpatizado con el capitalismo, por oponerse al comunismo, pero sin una mirada crítica. A su vez, los jóvenes de la Acción Católica, que muestran preocupación por estas urgentes demandas, han sido tachados por los mismos obispos como cercanos al comunismo?

La situación religiosa en Chile, para Hurtado, es aún más desconcertante que la situación social. Ve con gran preocupación que un porcentaje de la población, si bien es bautizada, muy pocos realmente viven y practican el cristianismo. El pueblo, aunque recibe los sacramentos, tiene una pésima formación religiosa. Estima que, de los 5 millones de población de los chilenos de la década, 4 millones quedan fuera de la acción de la Iglesia. No ha encontrado ninguna parroquia que supere el Io\% de la población practicante de la misa dominical. La Acción Católica es paupérrima y si no se hace algo simplemente, augura Hurtado, morirá pronto. Por esto urge penetrar en los problemas sociales, porque según él, a la base de la población aún hay huellas del cristianismo, pero necesitan que la Iglesia preste real atención a sus demandas humanas ${ }^{8}$.

Respecto a la situación política, Hurtado denuncia que el gran quiebre, entre la clase obrera y la Iglesia, se originó por la posición política, que esta última tomó frente al avance del laicado y del liberalismo, como consecuencia de una política internacional resonante incluso en nuestro país. Frente a esto, una gran parte de los laicos católicos se organizaron dentro del Partido Conservador y fueron apoyados por muchos obispos. Fruto de aquello, la Iglesia terminó apoyando a los latifundistas, dejando en la periferia los problemas reales y acuciantes de la clase obrera. Los jóvenes católicos del Partido Conservador, que siguieron los lineamientos de la DSI, se reagruparon en un nuevo bloque que se denominó Falange Nacional. Sin embargo, al poco tiempo, este nuevo bloque se separó del Partido Conservador para formar un nuevo partido. Las discrepancias

7 Cf. Ibíd.

8 Cf. Ibíd.

Facultad de Ciencias Religiosas y Filosóficas - Universidad Católica del Maule 
internas que se vivieron dentro de los católicos respecto de las posiciones políticas, incluso en una lectura atenta a la DSI, permitió nuevas fronteras a la Iglesia para no identificarla con un solo sector político-social ${ }^{9}$. De todos modos, esto fue insuficiente.

Estos antecedentes contextuales fueron de carácter urgente para san Alberto Hurtado y, por eso, su intención fue instar a su Santidad, por la promoción de una cultura del laicado cristiano, con respeto ante la jerarquía, pero alejada de los partidismos políticos para devolverle la confianza a la población, sobre todo, a la más vulnerable ${ }^{\mathrm{IO}}$. En este sentido, se ve la gran preocupación que tenía Hurtado por la formación de los laicos. Deseaba que fueran agentes pastorales reales de la acción cristiana en el país, y contribuyeran a subsanar las profundas desigualdades graves e inhumanas de las condiciones vitales para la gran mayoría. Todo lo dicho anteriormente es el trasfondo de su obra póstuma Moral Social.

\subsection{Fe y política ¿Una relación necesaria?}

En el prefacio a Moral Social, se vislumbra que la intención de la obra no es ser un libro de Doctrina Social de la Iglesia, sino una muestra de la profunda preocupación por el pobre ${ }^{\mathrm{II}}$. Lo que motiva esta obra es la preocupación por la calidad de vida que tenían la mayoría de los chilenos, situación a la que respondió con oído atento a la fe y a las implicancias sociales que lo interpelaron ${ }^{12}$. También, tuvo plena consciencia del contexto político del país, por lo que no pretendió alejarse de ella, sino que, más bien, procuró generar espacios de encuentro social precisamente a través de la política. Para el sacerdote jesuita, la mediación política iba más allá de los partidismos políticos. Estos más bien, buscaban el ejercicio del poder nominalmente, pero no desde el ejercicio que sirve como garante del bien común. Estaba convencido que los gobernantes y, en consecuencia, los políticos son los que tienen en sus manos el poder de propiciar reglas justas para toda la población. Ellos son los que deben buscar y difundir el bien común, que promueva la dignidad humana, la esperanza y la caridad cristiana $^{13}$. La política tiene fundamentalmente un carácter

\footnotetext{
9 Cf. Ibíd.

Io Cf. Ibíd.

II Alberto Hurtado, Moral Social (Santiago de Chile: Ediciones Universidad Católica de Chile, 2004), 9.

I2 Cf. Hurtado, Moral Social, Io.

I3 Cf. «Conferencia del Padre Hurtado en la Concentración Nacional de Dirigentes del Apostolado económico-social, en enero de 1950, en Cochabamba, Bolivia», en la web oficial sobre el Padre Alberto Hurtado, https://www.padrealbertohurtado.cl/distribucion-y-uso-de-la-riqueza-2/
} 
práctico, en el cual, para Hurtado, se coimplica con la fe cristiana:

Es necesaria la cooperación inteligente de los técnicos que estudien el conjunto económico-social del momento que vive el país y propongan medidas eficaces. Ha llegado la hora en que nuestra acción económico-social debe cesar de contentarse con repetir consignas generales sacadas de las encíclicas de los Pontífices y proponer soluciones bien estudiadas de aplicación inmediata en el campo económico-social. Tengo la íntima convicción de que si los católicos proponen un plan bien estudiado que mire al bien común, encontrará el apoyo de buenas voluntades que existen en todos los campos y se convertirá este plan en realidad ${ }^{14}$.

Alberto Hurtado no entendió la política como una mera búsqueda para ejercer el poder nominalmente, sino más bien en su sentido dativo, es decir, como un medio dentro de la polis que garantice la promoción del bien común. Así también lo deja entrever en la obra ¿Es Chile un país católico ${ }^{15}$, en la que encomia la labor que ha tenido la política como catapulta para llevar el catolicismo al ejercicio pleno de la sociedad civil, consiguiendo logros sociales y culturales ${ }^{16}$. Así mismo, interpela a la élite y la jerarquía eclesial, la cual ha su juicio, denuncia que se ha centrado únicamente en no perder el poder sobre las masas, alejándose verdaderamente de su misión social y humana. Por esto, Hurtado insta a los obispos a ir más allá de las cartas encíclicas, porque piensa que no están ayudando a subsanar los problemas de injusticia y, advierte con pesar, que tanto políticos como obispos las utilizan para perpetuarse en el poder ${ }^{17}$.

También, Hurtado indica la relevancia que debe existir entre la relación política y moral. En la introducción a la obra, señala que la actividad del ser humano tiene un aspecto individual y otro social, y según se observe, producirá diferentes organizaciones: la familia, la nación o los sindicatos. Sin embargo, el siglo XX estuvo marcado por una moral exclusivamente individual, lo que trajo como resultado un olvido

I4 "Conferencia del Padre Hurtado...», en la web oficial sobre el Padre Alberto Hurtado.

I5 Véase Alberto Hurtado, ¿Es Chile un país católico? (Santiago de Chile: Editorial Los Andes, I992), 27.

I6 Cf. Hurtado, ¿Es Chile un país católico?, 28. Destaca los ejemplos de Austria y Alemania, o el accionar de los pueblos mexicanos y españoles contra las políticas socialistas y comunistas, que viven ambos países en la primera mitad del siglo XX y que Hurtado, como también la Iglesia, ve como un peligro por los graves daños a la figura del hombre y del mundo.

I7 Ibíd. Se puede leer, en toda la obra, esta crítica a la élite social y económica, así como a la jerarquía eclesial chilena. 
de la moral social. Si bien es cierto que toda moral es individual, porque es finalmente un ser humano concreto quien hace el bien o el mal, aún en este sentido toda moral individual tiene implicancias sociales. Hurtado precisa que la moral, como estudio dentro de la Iglesia, ha procurado salvar al ser humano respecto de sus actos en el contexto social posterior a la revolución industrial, la cual ha dado lugar a grandes núcleos urbanos. La Iglesia está interpelada a dar una respuesta desde esta doble vertiente del hombre, individual y social, desde donde emana, al fin y al cabo, toda su existencia ${ }^{18}$.

Para Hurtado, la moral social católica no debe contentarse con afirmar solo lo que es lícito, sino que mira más lejos, ya que aspira a fundar las relaciones humanas en la justicia, la caridad y la equidad ${ }^{19}$. Tampoco debe buscarse solo en abstracto, ya que se necesitan técnicas concretas que materialicen la justicia y la caridad en los problemas urgentes: ¿cómo pagar salarios justos? ¿bajos qué medios? ¿buscando una deflación o una inflación para dar más puestos de trabajo? ¿abriendo nuevas industrias? ¿mejorando los precios, los productos? Todos estos son temas de la moral social y, por ende, de la política. No se puede pensar una moral social y una moral individual sin las técnicas que ofrece la economía y la política ${ }^{20}$.

San Alberto insta a vivir en la Iglesia desde distintos roles. Desde la acción católica, que refiere a la acción de evangelizar y cristianizar; desde la acción moral, que refiere a aquellos católicos comprometidos con el evangelio de Cristo cuyo obrar muestra una disposición a correr todos los riesgos que esta empresa conlleva: la organización de sindicatos, cooperativas y partidos políticos. Así, unos se esforzarán por bautizar católicos, y otros por construir un mundo más sano y más justo. Las dos acciones -la seglar y la religiosa-contribuyen a la creación del mundo que reclama en Evangelio de Cristo ${ }^{21}$.

En este sentido, el apartado siguiente se propone mostrar los sistemas o regímenes que estructuran económica y políticamente la sociedad, que se dieron -y se están dando- en Chile, así como en Occidente en general, y que Hurtado los sistematiza en su obra Moral Social. Al mismo tiempo, los presenta como propuestas insuficientes y generadoras de injusticias y desigualdades sociales. En concreto, se hace

I8 Hurtado, Moral Social, 23.

I9 Ibíd, 28.

2o Cf. Ibíd, 28-29.

2I Cf. Ibíd, 44 . 
referencia al régimen capitalista, al que, junto a otros sistemas, mueve con urgencia, a buscar medidas alternativas desde la moral social cristiana, para salvar la dignidad humana e instalar, en la política económica y social, el bien común.

\section{El capitalismo como estructura política y económica generadora de injusticias sociales en la obra Moral Social}

El problema tras la explicación y el análisis crítico que hace Hurtado sobre capitalismo se encuentra dentro de las distintas alternativas para solucionar la cuestión social, es decir, la cuestión de cómo se vive en una sociedad organizada de manera cultural, económica, política y religiosa. En la modernidad -específicamente en el contexto de la revolución industrial- surgieron distintos sistemas para organizar la vida social del ser humano, entre ellos: el liberalismo, el capitalismo, el marxismo, el comunismo y el catolicismo social ${ }^{22}$.

Para los efectos de esta investigación, se expondrán dos de estos sistemas presentados por el autor: el liberalismo y el capitalismo. Precisamente porque uno depende estructuralmente del otro y hay una correlación intrínseca desde donde surgen los cuestionamientos de nuestro autor. Y porque son los sistemas que hemos heredado en Chile. Si bien el socialismo y el marxismo han tenido eco en nuestra cultura, sobre todo durante los conflictivos años 60-70 en toda Latinoamérica, no son los sistemas que han dominado la estructura política y fundamentalmente económica de Chile ${ }^{23}$.

\section{I. Liberalismo}

El liberalismo, según Hurtado, se entiende desde la libertad como bien supremo del hombre. La libertad es el punto central de todo programa y de toda organización religiosa, política, económica y social. Trabajar por asegurar al máximo el uso de la libertad constituye el fin de tales organizaciones. Por lo tanto, el fin de la ley debe favorecer el desarrollo de las libertades individuales ${ }^{24}$. Hurtado distingue algunos tipos de liberalismo:

\footnotetext{
22 Cf. Ibíd, I50. Respecto del catolicismo social, nuestro autor señala que esta idea aún no ha sido depurada dentro de la misma Iglesia. Incluso se han dado diversas interpretaciones políticas con las consecuencias que ya expusimos en el apartado anterior.

23 Véase Carlos Ruiz y Sebastián Caviedes, «Estructura y conflicto social en la crisis del neoliberalismo avanzado», Espacio abierto: cuaderno venezolano de sociología 29, n. ${ }^{\circ}$ I (2020): 86-IOI. 24 Cf. Hurtado, Moral Social, I5I.
} 
a) Liberalismo absoluto: el fin supremo es la soberanía de la razón absoluta. Surge con Rosseau y su doctrina del contrato social. Fue difundida por los enciclopedistas franceses y luego conocida como la religión liberal. Con la conocida ausencia de Dios en la modernidad, el ser humano se eleva como fin absoluto y su libertad es precisamente el quid y quo que le concede licencias sin límites. Sin embargo, cuestiona Hurtado, las consecuencias sociales de esta libertad en la vida pública, le repugnan a la propia naturaleza humana que debe someterse a la pura razón, olvidando la relación del ser humano con Dios desde donde surgen las leyes humanas. En efecto, este liberalismo absoluto conduce a un estado ateo, que debe regirse únicamente por garantizar cualquier tentativa que se oponga a restringir la libertad de consciencia absoluta ${ }^{25}$.

b) Liberalismo mitigado: sus seguidores, teniendo conciencia de los vicios que trae un sistema de libertad absoluta, establecen como necesaria la relación de la libertad con la ley natural y la ley divina, mediante el recto uso de la razón. Para el santo jesuita, el problema radica en que estas leyes, para los liberales moderados, solo tienen incidencia en la vida privada y moral -o al menos en una parte de la moral-y, por consiguiente, no puede intervenir el Estado, porque en las cosas de uso público piensan los liberales moderados- no puede existir intervención de Dios. Es decir, la ley de Dios solo toca el ámbito de la consciencia privada, pero no la pública. De ahí que, en muchos casos, los que promueven esta tesis también promuevan, en lo económico y político, la separación de la Iglesia y el Estado ${ }^{26}$. Hurtado enfatiza que una libertad así no existe, y por lo mismo, debe ser cuestionada y criticada por la Iglesia.

c) Liberalismo económico: está estrechamente vinculado al dominio de la producción, transformación y repartición de la riqueza. La máxima detrás es la de los economistas del siglo XVIII, pertenecientes a la escuela de Manchester (dejad hacer, dejad pasar). Según ellos, la libertad económica con la libertad individual tenderán naturalmente a equilibrarse; por esto, el Estado no debe intervenir. El productor y el consumidor llegarán a la convicción que el equilibrio social se producirá una vez que entre ellos se entiendan. Los economistas liberales están atentos únicamente a los procesos económicos, no hay un trasfondo antropológico-filosófico como en el liberalismo absoluto o mitigado. Para ellos, la política económica es independiente de la moral. En este sentido, el mal aunque no querido es permitido en pro de esta relación (productor-consumidor). Hurtado los rebate, sosteniendo que la moral

25 Ibíd, I52-I53. 26 Ibíd, I53-I55. 
no está ausente de las leyes que rigen la economía y el Estado tiene la obligación de intervenir para salvaguardar la dignidad del más débil ${ }^{27}$.

d) Neoliberalismo económico: es un concepto acuñado en Francia (1938). Nace como crítica a la decadencia del liberalismo y sus ideales. Los neoliberales cuestionaron la pasividad del Estado, que no supo generar el equilibrio social-económico, puesto que, al no garantizar su arbitraje, se permitió la concentración de capitales y los monopolios mataron la competencia. ¿El resultado? El liberalismo cayó por no asegurar oportunamente una correcta participación. Para revertir la situación -proponen los neoliberales-, que es necesario una intervención del Estado que mantenga el equilibrio con el mercado libre. Pero san Alberto piensa que los neoliberales no ven que el problema está en el maquinismo y la técnica capitalista -que ha provocado la concentración de la producción-, sino que solo ven que el problema radica en la pasividad del Estado. Por esto, los problemas del liberalismo clásico continúan, porque continúa el fundamento individualista y la búsqueda de la mayor utilidad del mercado libre ${ }^{28}$.

\subsection{El capitalismo: un régimen injusto}

Para Alberto Hurtado, el capitalismo no es un sistema teórico, sino de orden práctico. En la encíclica Quadraggesimo anno, se habla de él como régimen, no como sistema: es una manera de proceder por el cual unos ponen el capital y otros el trabajo. Su característica fundamental es la separación de la sociedad en dos bandos: los capitalistas y los trabajadores ${ }^{29}$.

Hurtado, siguiendo al Papa Pío XI, resume las características más sustanciales del capitalismo en las siguientes: la acumulación de riquezas, la lucha por alcanzar el potentado económico, un inmenso predominio del capital sobre el trabajo (el capital es el dueño, el trabajo solo un servicio, un arriendo), se produce para ganar y no para servir, la filosofía dominante es el individualismo liberal, el instrumento de expansión es el crédito, la organización típica es la sociedad anónima, su fuerza en lo industrial es su racionalización, vive de un régimen de economía privada, reclama amplia independencia para las empresas y un tráfico abierto, y, por último, el capitalismo es técnico, científico de

27 Ibíd., I57-I58.

28 Ibíd., I63.

29 Ibíd., I64. Esta visión dialéctica será precisamente la gran crítica que le hará la Teología de la Liberación a la DSI en los 6os y 70 . 
aplicaciones revolucionarias desde el punto de vista orgánico ${ }^{30}$.

Dentro de las creaciones del capitalismo, que más critica Hurtado, se encuentra la sociedad anónima. Ésta tiene pretenciones democráticas, por ser una sociedad de responsabilidad limitada, pero en la práctica el interés privado de la sociedad, dominado por la idea de lucro, soslaya el principio del bien común. Las relaciones de la sociedad anónima con sus trabajadores son tan anónimas como su nombre lo indica, ya que, en general, los directorios no están en manos de los dueños. Los administradores -gerentes- deben entregar buenos dividendos; para ello, incluso los mismos trabajadores pagan el precio de esos buenos divendos, a costa de despidos, frecuentes abusos en los salarios y la constante indiferencia frente a los problemas reales de los trabajadores ${ }^{31}$. Si bien surgieron ideas para paliar los abusos de estas SS.AA., sostiene Hurtado, no son suficientes para mitigar el impacto en detrimento de los trabajadores y la sociedad en general ${ }^{32}$.

La concentración de la riqueza y del poder en manos de unos pocos, según Hurtado, es fruto del capitalismo y todo su aparataje técnico, lo que, a su juicio, ha deteriorado profundamente la sociedad. Porque se crean poderes y una prepotencia económica despótica en las manos de unos pocos, en las que muchas veces ni siquiera son los mismos dueños los que promueven malas prácticas, sino simplemente sus administradores, quienes, en definitiva, rigen el capital a su voluntad y arbitrio ${ }^{33}$. Así también, las nuevas formas de administración del capital (Trusts, Kartells, Consorcios y los Konzerne, los Holding, las Sociedades en cadena y las Agrupaciones de Sociedades Complementarias), que surgieron por las necesidades de la técnica moderna en el coste de la oferta-demanda, tuvieron-y tienen-graves consecuencias en la sociedad. A nivel nacional, por los enfrentamientos sociales que esto ha significado; pero también a nivel internacional, al pretender hegemonizar el poder económico en unos pocos con profundas consecuencias políticas. En el transcurso del siglo XX -y también en la actualidad- las consecuencias fueron acciones punitivas que arrastraron, tras ellas, el predominio de orden imperialista económico ${ }^{34}$. En este escenario, el bien común se difumina y la moral queda subordinada a los intereses de las nuevas necesidades del consumidor que, generalmente, son necesidades

\footnotetext{
30 Ibíd., I64-I65.

3 I Ibíd., I66.

32 Ibíd., I67-I68.

33 Ibíd., 168.

34 Ibíd., I70.
}

Palabra y Razón ISSN 24524646 versión en línea № 19 Julio de 202I 
inventadas al consumidor para producir más 35 .

Las concentraciones de poder, en efecto, acarrean graves injusticias sociales que destruyen al hombre y la mujer concretos, los cuales sufren las inclemencias de esa forma de organización social. Puesto que, frente al poder de unos pocos, no solo está en juego la justa distribución del capital, sino la integridad y la vida de quienes simplemente no pueden competir contra aquellos grupos en poder del capital. Y, por lo tanto, sufren el olvido de las estructuras que podrían ser sus garantes y sus oyentes.

En atención a lo mencionado anteriormente, Hurtado postula que, en su época, el capitalismo dentro del catolicismo ${ }^{36}$, no ha sido lo suficientemente cuestionado. Y advierte el grave peligro que encierra la tendencia a la acumulación y concentración de la riqueza en manos de unos pocos en detrimento de otros muchos. Esto se vuelve un problema moral para el cristianismo, porque conlleva el problema de querer siempre seguir aumentando los bienes, con las sucesivas consecuencias morales que esto implica, sobre todo para el prójimo y la vida en sociedad, tal como ha sido advertido por grandes profetas y santos en la Iglesia ${ }^{37}$. Según Hurtado:

El capitalismo tal y como ha vivido hasta ahora no puede ser una solución admisible para el católico. Los juicios de los papas y prelados constituyen un verdadero plebicito que los condena. Los católicos, por tanto, han de buscar otro regimen que evite esos errores de injusticia o han de depurarlo de sus vicios. Si el capitalismo quiere sobrevivir debe evitar la concentración de poder con su consiguiente deshumanización; debe terminar con el dominio del trabajo, que es inmensamente más noble, es algo humano-divino a pesar de las humildes apariencias ${ }^{38}$.

La conclusión de Hurtado, en su obra Moral Social, es que el régimen capitalista, así como los otros sistemas que se han originado

35 Ibíd., I7I.

36 Dentro del cristianismo católico, el capitalismo ha tenido distintas interpretaciones según el punto de vista desde el que se comprenda. Para algunos está condenado por la Iglesia y, para otros no, incluso algunos en los tiempos de san Alberto, lo consideraban la única vía alternativa al marxismo. Sin embargo, con el correr del tiempo y en el transcurso del siglo XX, así como el siglo XXI, cada vez podemos notar con más dureza la posición que ha tomado la Iglesia frente al capitalismo neoliberal. Varias son las encíclicas que dan cuenta de ello. El pontificado del Papa Francisco es el que con mayor agudeza ha enfatizado esta crítica.

37 Hurtado, Moral Social, I72-I73.

38 Ibíd., I73. 
en la sociedad moderna, como el socialismo y el marxismo ${ }^{39}$, son injustos cuando olvidan al ser humano y su relación con Dios. Cuando las normas y leyes, que rigen la sociedad civil, se apartan del derecho natural y excluyen a los pobres. Si se quiere pensar en un sistema que contemple la re-educación del ser humano en la sociedad debe "ser ante todo espiritual y religiosa y debe partir de Cristo como su fundamento indispensable, tener la justicia como su ejecutora y por corona la caridad" 40 .

\section{Alberto Hurtado hoy: una evaluación desde la Doctrina Social de la Iglesia y un breve contexto a la Iglesia en democracia}

Lo expuesto anteriormente interpela a la pregunta como cristianos católicos hoy, a 69 años de su muerte, sobre si hemos sido capaces de construir una Iglesia más profética acorde a Jesús y su mensaje evangélico. Las preocupaciones de Alberto Hurtado, como bien lo señala al comienzo de su obra, son las preocupaciones por los pobres y los excluidos del sistema. El propósito de Moral Social es generar, en la reflexión cristiana, las preguntas nunca bien ponderadas sobre el ser humano, su destino y las consiguientes delimitaciones de su ser y quehacer en el mundo. Expuestos todos los antecedentes preliminares y contextuales, la obra continúa con una reflexión teológica desde la moral social y antropológica, poniendo en el centro la relación con Dios desde la dignidad humana y desde la justicia que nos corresponde como hijos de un mismo Padre ${ }^{41}$. En este sentido, la pregunta por el modo en que la Iglesia ha hecho frente a estas problemáticas desde la Doctrina Social y desde el contexto anterior a las crisis que Chile ha debido enfrentar en este último periodo. Si bien solo se esbozarán algunas ideas, éstas pueden servir para una reflexión que a la postre oriente el contexto socio-político y religioso. De este modo, se tratará de recordar y volver a poner en la palestra la importancia que le dio san Alberto Hurtado a la caridad de la mano de la justicia; dos virtudes cristianas y humanas que la Iglesia está interpelada per se a promover en el diálogo fe y política, si en verdad quiere anunciar el Reino.

\section{I. Doctrina Social de la Iglesia: una crítica necesaria}

39 Que como hemos dicho no lo hemos considerado en este trabajo, por tratarse exclusivamente del pensamiento de Hurtado sobre el capitalismo. Sin embargo, la obra también le dedica interesantes apartados que los exponen al mismo tiempo, que denuncia sus limitaciones y pecados contra la moral y la leyes de Dios.

40 Hurtado, Moral Social, 201.

4I Ibíd., 2OI-209. 
La Doctrina Social de la Iglesia es por antonomasia la rama de la teología católica, especificamente de la moral social, que ha estudiado estos problemas y que ha tratado de dar soluciones cristianas a la vida del ser humano en sociedad. Sin embargo, su origen comenzó a ser fuertemente cuestionado en la segunda mitad del siglo XX. Teólogos latinoamericanos realizaron críticas epistémicas y estructurales a la DSI, las que resultan interesantes de poder recoger en este trabajo por dos motivos: por un lado, llama la atención que Alberto Hurtado no titulara su obra como Doctrina Social de la Iglesia sino Moral Social y, que, incluso, en una de las cartas dirigida a unos amigos, diga expresamente que no se trata de una obra sobre DSI, porque el trasfondo es su profunda preocupación por el pobre ${ }^{42}$. Y, por otro lado, como bien expuso a Pío XII, la DSI provocó discrepancias entre los conservadores y el Partido Falangista, arrojando dos maneras distintas de interpretarla ${ }^{43}$, lo que generó que Hurtado propusiera su revisión.

Si bien, desde san Alberto, no tenemos los antecedentes que nos permitan criticar la DSI -más que lo mencionado-, es interesante notar que las críticas más contundentes nacieron en la segunda mitad del siglo XX, de la mano de teólogos latinoamericanos preocupados por los problemas socio-políticos y económicos de América Latina que tuvieron escenario en este periodo histórico. Estos teólogos fueron configurando un nuevo paradigma y enfoque teológico que dio origen a la llamada Teología de la Liberación (=TL) ${ }^{44}$.

En este contexto, el teólogo chileno Sergio Silva Gatica señala que la primera gran crítica hacia la DSI -que emergió desde la TL-fue que no respondía a las problemáticas concretas de los países latinoamericanos, puesto que su origen era el contexto de países industrializados y como respuesta al comunismo de Marx -que se inicia con la encíclica Rerum Novarum en I89I-. Lo que elaboró, desde la fe, planteos sociales competitivos en el contexto europeo y desde una sola posición en el plano moral. La pregunta de la DSI, al fin y al cabo, es cómo vivir más

\footnotetext{
42 Ibíd., 9.

43 Véase, por ejemplo, Enrique Brahm García, «¿Doctrina Social de la Iglesia o liberalismo? Síntomas de división en el partido conservador entre los meses finales del gobierno de Ibáñez y la República Socialista de I932 en la prensa conservadora», Teología y Vida 59, n. ${ }^{\circ} 3$ (2018): 43I-460. 44 Cf. Pontificia Comisión Bíblica, La interpretación de la Biblia en la Iglesia (Santiago de Chile: San Pablo-Paulinas 1994) 69-73. La TL fue reconocida por la Pontificia Comisión Bíblica como un método de acercamiento contextual que permite el desarrollo hermenéutico de la Biblia y la realidad, sobre todo, de las víctimas de las injusticias sociales. Surgió en los años 7os, movido por dos grandes acontecimientos eclesiales, a saber, el Concilio Vaticano II y su declarada preocupación por los problemas contemporáneos, y la za Asamblea del CELAM en Medellín en 1968, que aplicó las enseñanzas del Concilio a las necesidades de América Latina.
} 
moralmente dentro del sistema capitalista ya existente, por lo que otra vía distinta al capitalismo queda fuera de la perspectiva y alcance de la $\mathrm{DSI}^{45}$. En este sentido, Hurtado tampoco plantea un sistema económico y político alternativo al capitalismo, pero invita a re-pensarlo desde la justicia y la caridad cristiana para humanizar los sistemas que están a la base de las sociedades modernas ${ }^{46}$.

La segunda gran crítica a la DSI, señalada por Silva, es el origen metafísico-filosófico que la sustenta, ontologizando la realidad hacia una dimensión estática, esencialista, abstracta y a-histórica, que la hace imposible a la realidad latinoamericana, con condiciones históricas y culturales diferentes. El mejor ejemplo es el de la propiedad privada. La DSI no se cuestiona su efectividad en Latinoamérica, donde la propiedad está en manos de unos pocos y para los otros -que son la mayoría- es imposible obtenerla bajo las estructuras económicas dominantes. Si bien, la DSI le da un rol garante al Estado, éste no puede imponerse sobre

45 Sergio Silva, La teología latinoamericana de la Liberación en sus inicios. Un intento de comprensión, Anales de la Facultad de Teología LXVI (n. ${ }^{\circ}$ Io7) (Santiago de Chile: Pontificia Universidad Católica de Chile, 20I6), I65. Sin embargo, es importante indicar que efectivamente la TL fue un intento dentro de la Iglesia que permitió una nueva orientación en el diálogo fe y política pero que, tampoco logró imponerse como idea política en el plano de la moral social y política cristiana, al menos en América Latina. Por el contrario, así como su nacimiento surgió con una fuerte veta política ligada al socialismo católico, apenas el muro de Berlín cayó, cayeron también las ideas socialistas en la cultura occidental. Esto dejó sin proyecto histórico concreto a la TL, transformándose, en una crítica al capitalismo, pero sin un plan alternativo que diera origen a una nueva forma de pensar el mundo y su relación con la sociedad. Cf. Silva, La teología latinoamericana de la Liberación en sus inicios..., 193.

46 Para este punto sería interesante ver la crítica que hace Iván Petrella a la teología de la Liberación respecto de la férrea crítica que los teólogos de la liberación han hecho al capitalismo. Según Petrella la TL no nació para hablar de liberación sin más, sino para ayudar a hacerla realidad desde sus dos vertientes: la relectura de la tradición desde los oprimidos y la construcción de proyectos históricos que superen las estructuras de injusticia. Sin embargo, señala Petrella. que la TL luego de la caída del socialismo se ha quedado sin proyecto histórico y su teología se ha convertido en una teología profética de anuncio y denuncia, centrándose fundamentalmente en una crítica al capitalismo de corte monolítico que ve en todo capitalismo y a éste como el responsable de todo (Ellacuría y Boff). La TL siguió la teoría de dependencia de Gunder Frank y esto ha sido fatal puesto que limita la acción política a la sola revolución, que en la democracia actual es imposible, sumándole que su análisis político se basa en generalizaciones sin proponer un análisis concreto, punto de partida para plantear verdaderos cambios. La sola idea de pretender cambiar de golpe un sistema por otro, no solo parece ilusorio, sino que conduciría necesariamente a un desastre. Para proponer un cambio histórico profundo P. mira el recurso a la teoría social de R. Mangabeira Unger quien reconoce que no existen ideas monolíticas del capitalismo y el mercado pues estas son abstracciones, más bien impulsa la idea de mirar alternativas pluralistas que se dan dentro de una sociedad que es multifacética y dinámica, siguiendo las ideas propuestas de la teoría de la ciencia de P. Feyerabend y Lakatos, quienes afirman que no hay una "ciencia normal" correlativamente Laclau y Mouffe señalan que tampoco hay una "sociedad normal". Petrella entonces, propone la metodología seguida por Unge que se funda en la teoría social que es descriptiva y crítica y ayuda a trazar realmente un proyecto histórico porque al describirla reconoce la pluralidad de manifestaciones socio-políticas y de esta manera las puede criticar más allá de los sesgos ideológicos. Véase en Sergio Silva, La Teología de la Liberación de América Latina. Crónica y evaluaciones, Anales de la Facultad de Teología LXVI (n. ${ }^{\circ}$ Io6), (Santiago de Chile: Pontificia Universidad de Chile, 20I6), I87-20I. 
los intereses económicos particulares, por lo que una justa distribución de la propiedad, bajo esas normas, es casi imposible ${ }^{47}$.

En tercer lugar, el régimen industrializado europeo supone un salario justo como criterio de justicia. Pero, si los bienes productivos están en manos de unos pocos, la pregunta gira en torno a la libertad de los obreros para aceptarlo o rechazarlo ${ }^{48}$. Entonces, no se trata solo de dar salarios justos o mover ciertas piezas de un lado a otro, sino de provocar un cambio en la mentalidad. Siguiendo esta línea, Sergio Silva, citando a Porfirio Miranda señala lo siguiente:

En el sistema teológico-filosófico de Occidente (y sin desapercibir las diversísimas variedades) el problema social es nuevo. No sabría yo encarecer suficientemente esta constatación. Derivada de Platón y de Aristóteles, la cultura occidental -cuyo epicentro generador fue y sigue siendo la teología-filosofía cristiana- resultó inevitablemente aristocrática, privilegiada, incapaz de percibir la realidad más masiva e hiriente y urgente de nuestra historia. $\mathrm{Su}$ humanismo fue y es humanismo de pensamiento. Mental. Estetista. Y su 'Hombre', un abstracto, una esencia platónica valedera semper et pro semper; no la humanidad real de carne y hueso, de sangre y lágrimas y esclavitud y humillación y cárcel y hambres y sufrimientos indecibles. Cuando por fin, después de resistencias y endurecimientos milenarios, esa cultura accedió condescendientemente a percatarse de que el problema social existe, tenía fatalmente que asignarle lugar de escolio, de excurso, de cuestión colateral complementaria, pasablemente marginal en el sistema; el sistema cultural se había estructurado de todo a todo prescindiendo del problema social; éste no le había hecho la menor falta para redondearse monolítico y sin grietas; le es imposible ahora encararlo en su verdadera dimensión sin desestructurarse a sí mismo por completo. Quien crea que es posible un cambio total de actitud sin cambio total de sistema mental, no sabe lo que es un sistema mental ${ }^{49}$.

Para Silva, la conclusión es clara: urge una reformulación radical a la DSI que incluya los problemas concretos de cada región, pero también insiste en el cambio de mentalidad que debe existir en la reflexión cristiana, sobre todo en América Latina, para que esos cambios lleguen

47 Íbid., I66.

48 Íbid., I68.

49 Ibíd., I67-I68. 
a las estructuras que sustentan las injusticias.

Si bien la DSI propone horizontes de las responsabilidades relativas a la construcción, organización y funcionamiento de la sociedad, haciendo énfasis particular en los desafíos que la Iglesia tiene en el mundo ${ }^{50}$, su fin no es delimitar un sistema o régimen políticoeconómico, sino mirar, estar atentos a la realidad en la que el ser humano vive siempre de cara a Dios. Sin embargo, uno de sus problemas es que a lo largo de su existencia se ha utilizado con fines políticos, donde algunos se centran en ciertos puntos, olvidando la mirada holística que toda doctrina moral-social cristiana debe comportar. En este sentido, aunque la crítica surge muchos años después de la muerte de Hurtado, no deja de sorprender la sintonía que tiene con lo planteado por el mismo. El problema, quizá, le latía, pero no era capaz aún de comprenderlo. Por esto, las críticas que sistematiza Sergio Silva son orientadoras, porque vislumbran un problema sustancial al que la Iglesia debe dar respuesta. Salir de la lógica dualista en la que el capitalismo ha puesto la sociedad (capital-trabajadores) es proponer una nueva mirada desde nuevas categorias antropológicas e incluso ecológicas y, ciertamente, hoy se puede ver un avance desde la DSI en estas materias ${ }^{51}$, tanto para América Latina como para nuestro propio país.

\subsection{La realidad de la Iglesia en Chile hoy}

En concordancia, la situación de la Iglesia chilena históricamente no ha sido muy distinta a la situación latinoamericana. La Iglesia en Chile respecto de su función orientadora en materias sociales, políticas y económicas ha tenido periodos dulces y otros agraces. Este apartado se centrará en mencionar brevemente el periodo que comprende la vuelta a la democracia, con el fin de poner un marco contextual que sirva para orientar una reflexión posterior que ilumine claves de acción desde la mirada de Hurtado.

La situación de la Iglesia hoy en Chile respecto de relación economíapolítica-fe, por decirlo de algún modo, es difícil, y por lo mismo, no se han dado fuertes críticas a los modelos socio-políticos que sustentan la vida social y económica de los chilenos desde la perspectiva de la fe de la

50 Cf. Ricardo Azael Escobar Delgado, «La Doctrina Social de la Iglesia: Fuentes, Principios y Concepción de los Derechos Humanos», Revista Prolegómenos. Derechos y Valores I5, n. 30 (2012): 99-II7.

5I Cf. Mauricio Víquez, «Globalización. Lectura crítica desde la Doctrina Social de la Iglesia», Espiga 8 (2003): I-I4. 
Iglesia $^{52}$.

Si bien, entre los años setenta y ochenta, la Iglesia tuvo un rol protagónico en materia social y política por su ardua defensa de los DD.HH., a partir de 1990 hubo un cambio imposible de revertir. Con la recuperación de la democracia, los temas sociales siguieron presentes, sobre todo por la urgente necesidad de descubrir la verdad respecto de lo sucedido en los tiempos de dictadura y, en consonancia, la búsqueda de la justicia para los casos de graves atropellos a los DD.HH..$^{53}$, que además se vio favorecido por los mismos objetivos de unidad del gobierno del presidente Aylwin.

Durante la década de 1990, los obispos siguieron preocupados de la situación social de los chilenos, transparentando las graves diferencias entre ricos y pobres, sobre todo porque las crisis económicas que se suscitaron desde los años ochenta tuvieron grandes y nefastas repercusiones en los más pobres. Si bien, en los años noventa, el país experimentó un progreso económico, el gran problema que comenzó a fraguarse fue que no llegó de manera equitativa a todos los sectores de la sociedad, provocando grietas y desigualdades socio-económicas, que tuvieron preocupados a los obispos de la época:

El éxito del desarrollo económico del país contrasta con la permanencia de fuertes desigualdades sociales. La violenta diferencia en la distribución de los ingresos es un llamado a la conciencia de cada uno, y también aparece como un elemento de riesgo para la mantención del crecimiento económico. Estamos ante el serio desafío de formar un país sustentable en el largo plazo, si sabe organizarse de manera equitativa y fraterna y no darnos por satisfechos con una simple bonanza que podría ser pasajera ${ }^{54}$.

Sin embargo, esta preocupación y defensa del más desvalido de la sociedad, prontamente se fue difuminando ${ }^{55}$, y los temas de la cultura y de la moral sexual fueron tomando cada vez más protagonismo en la Iglesia chilena, alineándose así con las preocupaciones del Papa Juan

52 Las declaraciones de las conferencias episcopales entre 1990 y el 2001 nos dan un marco de referencia para situarnos en este contexto.

53 Véase Comité Permanente, Buscamos la paz y el bien de todos (Santiago, Chile: Conferencia Episcopal de Chile, 1988).

54 Véase Comité Permanente, Mensaje en el Día de la Solidaridad (Santiago, Chile: Conferencia Episcopal de Chile, 1997).

55 Cf. Hannah Stewart-Gambino, «Las pobladoras y la Iglesia despolitizada en Chile», América Latina Hoy 4I (2005): I2I-I38. 
Pablo II. El divorcio, la eutanasia, el aborto, etcétera, tomaron las agendas de los obispos, porque estos eran los temas que, además, se debatían en el congreso ${ }^{56}$ y en la sociedad en general. A este respecto, es interesante notar que, si bien la Iglesia había tomado una posición política en tiempos de dictadura -más ligada a los partidos de izquierda-, a la vuelta de la democracia, en la derecha conservadora, encontró mayor sintonía, por la llamada agenda valórica que se toma las discusiones sociales y políticas.

De esta manera la Iglesia tuvo durante todos estos años éxito en la adaptación al contexto que ella misma había contribuido a crear. Durante los primeros tres años de la consolidación de la democracia las dificultades para adaptarse fueron mayores. No le resultaba fácil encontrar su lugar en un ambiente pluralista, liberal y democrático. Aprobó los procedimientos democráticos siempre y cuando no fueran divergentes con los intereses de la Iglesia. Para ello se encontró en la necesidad de buscar nuevos aliados, y los encontró en los partidos de derecha y conservadores, con sus dudosas posturas democráticas. La Iglesia se alió con fuerzas que un tiempo atrás habían sido sus adversarios políticos ${ }^{57}$.

De tal modo que la cuestión económica y social comenzó a ser abandonada por la política en general, y también por la Iglesia ${ }^{58}$. Poniendo en el centro del debate la cuestión de la moral sexual, se fue olvidando el carácter social de la moral, restringiéndola a lo sexual.

De esta manera, la cuestión social comenzó a reducirse. El

56 Por ejemplo, cultura y su evangelización: "Id y Anunciad el Evangelio". Carta del Comité Permanente con ocasión de los 500 años del inicio de la Evangelización de América, I2 de setiembre de 1992, Documentos del Episcopado 1992-1996, o.c., nos I8-20. "Comunicado de prensa. $73^{\text {a }}$ Asamblea Plenaria", I6 de mayo de 1997, Documentos del Episcopado 1997-200I, o.c., , nº 9. "Comunicado de prensa sobre la $75^{\text {a }}$ Asamblea Plenaria", I5 de mayo de I998, Ibídem, , nos 2-5. Dignidad de la procreación y respeto por la vida humana naciente". Comité Permanente, I2 de setiembre de 1996, Documentos del Episcopado 1992-1996, o.c., "Temas de bioética". Comité Permanente, I2 de marzo de 1997, Documentos del Episcopado I997-20oI, o.c., , n ${ }^{\circ}$ I. "En defensa de la vida humana". Comité Permanente, 20 de marzo de 20oI, Ibídem, . Ver "Comunicado de prensa. $72^{\text {a }}$ Asamblea Plenaria”, 22 de noviembre de 1996, Documentos del Episcopado 1992-1996, o.c., , nº 7 .

57 Cf. Veit Strassner, «La Iglesia chilena desde 1973 a I993: De buenossamaritanos, antiguos contrahentes y nuevos aliados. Un análisis politológico», Teología y Vida 47, n. ${ }^{\circ}$ I (2006): 76-94.

58 Ver por ejemplo el interesante artículo de Stewart-Gambino. En el se cita la opinión que tienen las pobladoras de las comunas santiaguinas como la Granja, Lo Espejo, sobre el rol que va adquiriendo la Iglesia a la vuelta de la democracia: "reconocen que las organizaciones populares creadas durante la dictadura-sobre todo las comunidades cristianas de base- han perdida fuerza. Reconocen también que se enfrentan a nuevos y numerosos obstáculos: la pérdida y el apoyo de la Iglesia, una clase política distante, una cultura política diferente (...). Lo que sí sienten más que todo es que se ven abandonadas, tanto por la Iglesia como por el Estado". Stewart-Gambino, «Las pobladoras y la Iglesia despolitizada en Chile», I30. 
ser humano se redujo a una dimensión más individualista ${ }^{59}$, con repercusiones incluso en la práctica religiosa, que se fue orientando cada vez más, hacia lo ritual como camino para una salvación que dejaba poco lugar y espacio al otro ${ }^{60}$.

\subsection{JUSTICIA Y CARIDAD COMO RESPUESTA AL CAPITALISMO}

Dado el contexto anterior, y enfatizando la urgente necesidad de volver a poner en la palestra la dimensión social del ser humano, en mundo atravesado por la ideología capitalista que pone en el centro al individuo, pero no a la persona como ser social, es bueno volver a releer aquellas unidades de sentido del mensaje cristiano. Por ello, la relevancia que Hurtado le dio a la dimensión de la caridad cristiana, en sintonía irrestricta con la justicia, nos devuelven el carácter humano de los sistemas sociales que legítimamente las sociedades construyen para ordenarse. Como se ha dicho, Hurtado no propone un sistema político-económico alternativo al capitalismo, pero si es enfático al señalar la importancia de devolverle, al capitalismo o cualquier sistema social, la impronta humana, porque todo sistema está configurado para los seres humanos. En este sentido, no solo para nuestro país, sino para cualquier sociedad, los aportes sobre la justicia y la caridad de Alberto Hurtado valen la pena revisarlos, sobre todo en el actual contexto de crisis sociales y económicas.

Para san Alberto, por un lado, la justicia es la disposición estable de nuestra voluntad, que nos impulsa a respetar el derecho del prójimo. Este derecho conlleva todas sus manifestaciones: bienes corporales y espirituales, que incluyen la salud, el honor, la riqueza, la libertad, las asociaciones, entre otras. En este sentido, es una obligación moral hacer justicia al otro $^{61}$. Aunque la justicia es impopular porque a primera vista no parece tan benevolente como la caridad, si se entiende esta última como limosna. El problema es que la línea entre la superioridad y la vanidad para quien realiza actos caritativos sin justicia, es muy delgada, y las consecuencias morales y prácticas pueden tender a un

59 Cf. Jorge Costadoat, «El catolicismo ante la individualización», Teología y Vida 45, n. ${ }^{\circ} 4$ (2004): 605-610.

6o El teólogo Jorge Costadoat señala refiriéndose a Hurtado que "se empeña en romper un concepto de vida espiritual que reduce el examen de conciencia al cuidado de la pureza; el espacio religioso, a la capilla; y la piedad, a los sacramentos y a unas cuantas prácticas devotas" , porque la verdadera devoción cristiana no se contenta con buscar a Cristo en el cielo y en la Eucaristía, sino en el prójimo en el servicio real a cada uno de nuestros hermanos. Y agrega Costadoat que, Hurtado, incluso, concibe que los no cristianos que practican la caridad, de igual modo llegan a Cristo, porque la verdad de Cristo se revela ahí donde se practica: Costadoat, «La "mística social" del Padre Hurtado", 289.

6I Hurtado, Moral Social, 213. 
proteccionismo social que está muy lejos de ser justicia para el otro:

Hay muchos que estarán dispuestos a hacer caridad pero no se resignan a cumplir con la justicia; están dispuestos a dar limosnas, pero no a pagar el salario justo. Aunque parezca extraño, es más fácil ser caritativo, (claro que solo en apariencia) que justo. Tal pretendida caridad no lo es, porque la verdadera caridad comienza allí donde termina la justicia. Caridad sin justicia, no salvará los abismos sociales, sino que creará un profundo resentimiento. La injusticia causa más males de los que puede reparar la caridad ${ }^{62}$.

Por otro lado, la justicia debe estar en plena concordancia con la búsqueda del bien común al que debe tender toda sociedad, procurándola desde sus aspectos particulares (justicia comuntativa y distributiva) -las que señala como básicas y elementales-, hasta los aspectos generales, en los que se encuentra la justicia social que es la encargada de promover el bien común a través de legisladores, gobernantes y magistrados ${ }^{63}$. Por esto, la justicia social debe entenderse en dos sentidos: en primer lugar, los servidores del bien común deben tener plena consciencia que las sus- acciones tendrán repercusiones en la sociedad; y, en segundo lugar, todos los que comprenden una sociedad, deben tener un profundo sentido de responsabilidad, para generar un espacio social libre de odios e inequidades ${ }^{64}$. En consecuencia, la justicial social es deber de todos, pero, para Hurtado, quienes tienen la mayor responsabilidad de velar por su ejercicio, son aquellos que ocupan un lugar en el campo de la reflexión intelectual y aquellos que gobiernan y dirigen una sociedad ${ }^{65}$.

Finalmente, la justicia no se puede entender sin la caridad. Hurtado recuerda que todo ejercicio de justicia emana del amor misericordioso de Dios hacia sus hijos. La caridad cristiana es una acción de amor al prójimo a la manera de Cristo y no un simple acto de derecho al otro, sino por sobre todo un acto de amor, benevolente, que emana de la Gracia del Padre. Justicia y caridad se complementan, porque movidos por el amor, el corazón humano se ubica en el lugar del otro para hacerle justicia restituyéndolo en el lugar que le corresponde como prójimo y como hijo, es decir, en el lugar y espacio fraterno que le corresponde como hermano, heredero de la misma tierra para todos los seres humanos ${ }^{66}$.

62 Ibíd., 2I4.

63 Ibíd., 216.

64 Ibíd., 218.

65 Ibíd., 219.

66 Cf. Ibíd., 220-22I. 
Por último, y no menos importante e interesante, de acuerdo con Hurtado, cuando las sociedades se olvidan de practicar la justicia y la caridad, la parte a la que se le debe la justicia -que suele ser la mayor parte- termina resintiéndose, incubando una pasión por la justicia que puede estallar con una fuerza debastadora ${ }^{67}$. Sin duda, palabras muy profundas que interpelan nuestro contexto actual de manera arrolladora.

El olvido de la fe y la política hacia el más débil, al que se le debe la práctica de justicia y la caridad -lo que tanto temía Hurtado-, dejó la cancha dispuesta para que el capitalismo de corte neoliberal se desenvolviera, sin intervención del Estado, sin una crítica contundente desde la Iglesia por su intrínseca generación de desigualdades, tal como deseaba el liberalismo: que esperaba la tendencia natural de las dos posiciones sociales (capitalistas y trabajadores) al equilibrio. No obstante, la realidad dijo lo contrario, y en el 2019 se desató una profunda crisis social y económica en Chile que, hasta la fecha, nadie ha podido responder. Quizá Carlos Peña tenga razón: la política y la religión han estado ausentes.

\section{Conclusión}

Vivimos en una sociedad que puso como premisa lo siguiente: de religión y de política no se habla. Sin embargo, lo expuesto por Alberto Hurtado interpela a buscar puentes de unidad y diálogo entre la fe y la política porque ambas se co-implican mutuamente. El contexto socio-político y religioso del ser humano, ciertamente, marca la vida en sociedad $y$, cuando una abandona a la otra o solo se utilizan instrumetalmente entre sí, las consecuencias las viven fundamentalmente los sectores más vulnerables de la sociedad.

El capitalismo neoliberal es el regimen que se impuso en la política y la economía occidental y, por su puesto, tuvo eco en Chile. Y al no tener una crítica contundente sobre su aplicación a la vida social, y dejando actuar todos sus aparatos técnicos a nivel laboral, educaciónal e incluso filosófico -el liberalismo-, fue dejando grietas en la vida y en las relaciones éticas y espirituales de los ciudadanos, a los que la Iglesia Católica no supo dar respuestas en el momento oportuno. Es cierto que durante su implementación han surgido críticas. Tanto la Rerum Novarum como el posterior desarrrollo de la DSI -que sin duda fueron grandes aportes-, en la práctica no generaron el impacto social esperado.

67 Ibíd., 2I4. 
Las causas, evidentemente, son mucho más extensas y profundas que lo que este trabajo pudo abordar; no obstante, las mencionadas ayudan e iluminan a seguir buscando luces que permitan plantear un modelo de vida más justo donde la caridad y la justicia caminen de la mano para resolver los problemas sociales que vivimos como sociedad en la actualidad.

Alberto Hurtado no fue un teólogo en el sentido estricto de la palabra. Fue más bien un testigo de Cristo, que supo mirar la realidad de los que sufren y relacionarse con ellos, entenderlos teniendo siempre presente su consigna: ¿Qué haría Cristo en mi lugar? En este sentido, insta a los católicos en Chile a poner al prójimo -sobre todo el más débilcomo un rostro de Cristo, y desde ahí hacerle justicia como otro Cristo. Es decir, para encontrarse con Cristo, no bastan los ritos ni la Eucaristía, sino la vida compartida con el otro al que hago mi prójimo por amor a Cristo y su Iglesia. 
